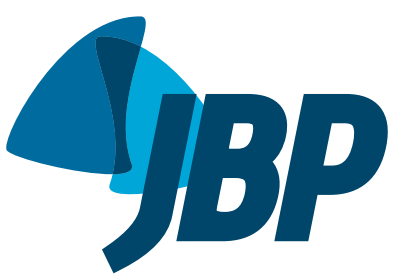

\title{
Electronic cigarettes - the new playbook and revamping of the tobacco industry
}

\author{
Ubiratan Paula Santos ${ }^{1, a}$
}

The smoking epidemic began in the late nineteenth century, driven by the invention of the cigarette making machine. In the twentieth century, it was driven by the advertising industry, the cinema, and the great wars, as well as by the greater circulation of goods and people. The major health hazards of tobacco use have been consistently demonstrated since 1950. (1) Beginning in the 1990s, efficient anti-smoking policies gained momentum worldwide ${ }^{(2)}$, thus reducing the impact on public health. In Brazil, the implementation of anti-smoking policies, such as a ban on cigarette advertising, warnings on cigarette packs, increased dissemination of information about the harmful effects of tobacco use, a ban on smoking in enclosed spaces, an increase in the price of tobacco products, and the expansion of smoking cessation support services, contributed to a significant reduction in the prevalence of smoking among males and females ${ }^{(3)}$, which fell from $43.3 \%$ and $27.0 \%$, respectively, in $1989^{(4)}$ to $12.6 \%$ and $8.2 \%$, respectively, in 2015 . $^{(5)}$ However, worldwide and in Brazil, smoking is still the second leading risk factor for mortality, there having been an estimated 7.13 million smoking-related deaths in 2016. ${ }^{(6)}$ In addition, approximately 1.1 billion people $\geq 15$ years of age still smoke. ${ }^{(7)}$

In reaction to the world closing ranks against tobacco use, the recent efforts to ban the use of flavorings, and the imposition of laws to make cigarette packaging more generic, the tobacco industry has devised new strategies. The industry seeks to present itself as a defender of public health, has finally recognized the harmful effects of smoking, and has begun to offer alternatives. It has started to produce products such as electronic cigarettes (e-cigarettes, heating to near $100^{\circ} \mathrm{C}$ ) and vape pens (vaporizers, heating to near $300^{\circ} \mathrm{C}$ ), both of which supply nicotine in a heated form.

The topic of the moment is the controversy among researchers and medical societies about the use of e-cigarettes to reduce harm or as another treatment option for smoking cessation. (8-11) $^{-}$This new strategy of the tobacco industry-investing in e-cigarettes and vaporizers as a way of offering nicotine to current smokers and of encouraging smoking initiation-has been the subject of studies worldwide. By manufacturing vaporizers with attractive designs and adding flavorings to e-liquids, the tobacco industry seeks to attract new users, especially young ones, as a means of maintaining the numbers of individuals who are dependent on nicotine, stimulating dual consumption-the burning of tobacco and the vaporizing of nicotine in electronic devices-and thus retaining its lucrative market.
A growing number of studies provide evidence of increased e-cigarette use by young people and that those individuals are more likely to become regular users of tobacco products, due to the perception of reduced risk, and to become addicted to nicotine. ${ }^{(12)}$ Those factors, together with the risks of e-cigarettes, which contain not only nicotine, an addictive substance that increases the risk cardiovascular disease, but also numerous toxic chemicals $^{(13)}$ and offer a quantity of inhaled particles that far exceeds the recommended limit for environmental exposure to particulate matter, ${ }^{(14)}$ have led international respiratory medical societies ${ }^{(12)}$ to recommend that the devices be classified and regulated as tobacco products, that their sales to minors be prohibited, and that there be a ban on their use in enclosed spaces (i.e., that they be considered to have a negative environmental impact), encouraging further studies on their effects.

In the study conducted by Oliveira et al., ${ }^{(15)}$ published in this issue of the JBP, the authors evaluated awareness of e-cigarettes and the frequency of experimentation with/ use of the devices on the part of university students. They found that $37 \%$ were aware of e-cigarettes, $2.7 \%$ had it experimented with them, and $0.6 \%$ used them regularly. The prevalence of e-cigarette use was associated with being younger, having parents with a higher level of education, and having smokers in the family. ${ }^{(15)}$ Although the prevalence of regular e-cigarette use was lower than that reported for other countries, ${ }^{(16,17)}$ as well as being lower that reported in a study evaluating a sample of individuals over 18 years of age in the Brazilian cities of Rio de Janeiro, São Paulo, and Porto Alegre, ${ }^{(18)}$ the Oliveira et al. study ${ }^{(15)}$ calls attention to the high rate of awareness of e-cigarettes.

A recently published study, conducted in Canada and involving more than 28,000 individuals of both sexes (15-54 years of age), underscores the need for more attention to be given to the subject. (19) That study revealed that $7.7 \%, 6.0 \%$, and $4.9 \%$ of the participants made use of conventional cigarettes only, e-cigarettes + conventional cigarettes, and e-cigarettes only, respectively. The authors found that the level of exposure to environmental tobacco smoke (ETS) was higher among the users of e-cigarettes + conventional cigarettes than among the users of conventional cigarettes only. Although the level of ETS exposure among exclusive users of e-cigarettes was lower than that observed for exclusive users of conventional cigarettes, it was still higher than the level of ETS exposure observed for never-smokers, which provides evidence of the behavioral profile of the e-cigarette user. 
In Brazil, the implementation of the abovementioned anti-smoking policies is responsible for the sharp drop in the prevalence of smoking, which should discourage the adoption of policies allowing the marketing of yet another product by the tobacco industry, whether as a strategy for reducing risks or as a tool for promoting smoking cessation. While we await additional research on the impact of the chronic use of the new devices, there are other measures that can be implemented: banning the use of flavorings in cigarettes; curbing the traffic in contraband cigarettes; eliminating the sale of loose cigarettes at newsstands and other outlets; and expanding smoking cessation support services.

Why should a doctor prescribe a product made by the same industry that, despite having been aware of the disastrous health impacts that its products have, has always been slow to admit that there is such an impact and that nicotine is in fact addictive, steadfastly refusing to pay reparations to its victims, as demonstrated by the exhaustive collection of documents produced by the tobacco industry itself and released to the public in recent decades? ${ }^{(20)}$ On the basis of the current knowledge, there is no reason.

\section{REFERENCES}

1. DOLL R, HILL AB. Smoking and carcinoma of the lung; preliminary report. Br Med J. 1950;2(4682):739-48. https://doi.org/10.1136/ bmj.2.4682.739

2. World Health Organization. WHO Framework Convention on Tobacco Control Geneva: World Health Organization; 2005.

3. Levy D, de Almeida LM, Szklo A. The Brazil SimSmoke policy simulation model: the effect of strong tobacco control policies on smoking prevalence and smoking-attributable deaths in a middle income nation. PLoS Med. 2012;9(11):e1001336. https://doi. org/10.1371/journal.pmed.1001336

4. Monteiro CA, Cavalcante TM, Moura EC, Claro RM, Szwarcwald CL. Population-based evidence of a strong decline in the prevalence of smokers in Brazil (1989-2003). Bull World Health Organ. 2007;85(7):527-34. https://doi.org/10.2471/BLT.06.039073

5. GBD 2015 Tobacco Collaborators. Smoking prevalence and attributable disease burden in 195 countries and territories, 19902015: a systematic analysis from the Global Burden of Disease Study 2015. Lancet. 2017;389(10082):1885-1906. https://doi.org/10.1016/ S0140-6736(17)30819-X

6. GBD 2016 Risk Factors Collaborators. Global, regional, and national comparative risk assessment of 84 behavioural, environmental and occupational, and metabolic risks or clusters of risks, 1990-2016: a systematic analysis for the Global Burden of Disease Study 2016 Lancet. 2017;390(10100):1345-422. https://doi.org/10.1016/S0140 6736(17)32366-8

7. Drope J, Schluger NW, editors. The Tobacco Atlas. 6th edition Atlanta (GA): American Cancer Society, Vital Strategies; 2018

8. Dautzenberg B, Adler M, Garelik D, Loubrieu JF, Mathern G, Peiffer $G$, et al. Practical guidelines on e-cigarettes for practitioners and others health professionals. A French 2016 expert's statement Rev Mal Respir. 2017;34(2):155-164. https://doi.org/10.1016/j. rmr.2017.01.001

9. Yeh JS, Bullen C, Glantz SA. CLINICAL DECISIONS. E-Cigarettes and Smoking Cessation. N Engl J Med. 2016;374(22):2172-4. https://doi. org/10.1056/NEJMclde1602420

10. Aveyard P, Arnott D, Johnson KC. Should we recommend e-cigarettes to help smokers quit? BMJ. 2018;361:k1759. https://doi. org/10.1136/bmj.k1759

11. Schraufnagel DE, Blasi F, Drummond MB, Lam DC, Latif E, Rosen
MJ, et al. Electronic cigarettes. A position statement of the forum of international respiratory societies. Am J Respir Crit Care Med. 2014;190(6):611-8. https://doi.org/10.1164/rccm.201407-1198PP

12. Ferkol TW, Farber HJ, La Grutta S, Leone FT, Marshall HM, Neptune $E_{\text {, et }}$ al. Electronic cigarette use in youths: a position statement of the Forum of International Respiratory Societies. Eur Respir J. 2018;51(5). pii: 1800278. https://doi.org/10.1183/13993003.002782018

13. Benowitz NL, Fraiman JB. Cardiovascular effects of electronic cigarettes. Nat Rev Cardiol. 2017;14(8):447-456. https://doi. org/10.1038/nrcardio.2017.36

14. Zervas E, Litsiou E, Konstantopoulos K, Poulopoulos S, Katsaounou $P$. Physical characterization of the aerosol of an electronic cigarette: impact of refill liquids. Inhal Toxicol. 2018; Sep 26:1-6. [Epub ahead of print] https://doi.org/10.1080/08958378.2018.1500662

15. Oliveira WJC, Zobiole AF, Lima CB, Zurita RM, Flores PEM, Rodrigues LGV, et al. Electronic cigarette awareness and use among students at the Federal University of Mato Grosso, Brazil. J Bras Pneumol. 2018;44(5):367-9. https://doi.org/10.1590/S180637562017000000229

16. Gravely S, Fong GT, Cummings KM, Yan M, Quah AC, Borland $\mathrm{R}$, et al. Awareness, trial, and current use of electronic cigarettes in 10 countries: findings from the ITC Project. Int J Environ Res Public Health. 2014;11(11):11691-704. https://doi.org/10.3390/ ijerph111111691

17. Knorst MM, Benedetto IG, Hoffmeister MC, Gazzana MB. The electronic cigarette: the new cigarette of the 21st century? J Bras Pneumol. 2014;40(5):564-72. https://doi.org/10.1590/S180637132014000500013

18. Cavalcante TM, Szklo AS, Perez CA, Thrasher JF, Szklo M, Ouime $\mathrm{J}$, et al. Electronic cigarette awareness, use, and perception of harmfulness in Brazil: findings from a country that has strict regulatory requirements. Cad Saude Publica. 2017;33Suppl 3(Suppl 3):e00074416. https://doi.org/10.1590/0102-311X00074416

19. Nguyen HV, Sheikh A. Environmental tobacco smoke exposure among electronic cigarette users. Addict Behav. 2018;89:92-97. https://doi.org/10.1016/j.addbeh.2018.09.026

20. Cummings KM, Brown A, O'Connor R. The cigarette controversy. Cancer Epidemiol Biomarkers Prev. 2007;16(6):1070-6. https://doi. org/10.1158/1055-9965.EPI-06-0912 